\title{
Effect of calcination temperature on structural properties and photocatalytic activity of $\mathrm{Mn}$-C-codoped $\mathrm{TiO}_{2}$
}

\author{
Jianbo Cai ${ }^{a}$, Wei Xin ${ }^{a}$, Guanglong Liu ${ }^{a *}$, Die Lin ${ }^{a}$, Duanwei Zhu ${ }^{a}$ \\ ${ }^{a}$ Laboratory of Eco-Environmental Engineering Research, College of Resources \& Environment, \\ Huazhong Agricultural University - HZAU, Wuhan 430070, China.
}

Received: July 1, 2015; Revised: November 19, 2015; Accepted: December 27, 2015

\begin{abstract}
Mn-C-codoped $\mathrm{TiO}_{2}$ catalysts were synthesized by modified sol-gel method based on the self-assembly technique using polyoxyethylenesorbitan monooleate (Tween 80) as template and carbon precursor and the effect of calcination temperature on their structural properties and photocatalytic activity were investigated. The XRD results showed undoped and $\mathrm{Mn}$-C-codoped $\mathrm{TiO}_{2}$ calcined at $400{ }^{\circ} \mathrm{C}$ only include anatase phase and the rutile phase appears when the calcination temperature reached to $600^{\circ} \mathrm{C}$. UV-vis absorption spectroscopy demonstrates that the absorption spectra are strongly modified by the calcination temperature. Moreover, the $\mathrm{Mn}-\mathrm{C}-\mathrm{TiO}_{2}$ calcined at $400{ }^{\circ} \mathrm{C}$ showed the lowest PL intensity due to a decrease in the recombination rate of photogenerated electrons and holes under light irradiation. The photocatlytic activity of $\mathrm{Mn}-\mathrm{C}$-codoped $\mathrm{TiO}_{2}$ were evaluated by the degradation of methyl orange (MO) under the simulate daylight irradiation and all the prepared $\mathrm{Mn}-\mathrm{C}$-codoped $\mathrm{TiO}_{2}$ samples exhibited high photocatalytic activities for photocatalytic decolorization of methyl orange aqueous solution. At $400{ }^{\circ} \mathrm{C}$, the $\mathrm{Mn}$-C-codoped $\mathrm{TiO}_{2}$ samples showed the highest photocatalytic activity due to synergetic effects of good crystallize ation, appropriate phase composition and slower recombination rate of photogenerated charge carriers, which further confirms the calcination temperature could affect the properties of $\mathrm{Mn}-\mathrm{C}-$ codoped $\mathrm{TiO}_{2}$ significantly.
\end{abstract}

Keywords: $\mathrm{Mn}$-C-codoped, Tween 80, Methyl orange, Calcination temperature, $\mathrm{TiO}_{2}$

\section{Introduction}

Photocatalytic degradation of toxic organic compounds has received a great attention for the past several years. Due to its strong oxidizing powder, cost-effective, and long-term stability against photo and chemical corrosion, $\mathrm{TiO}_{2}$ has been used widely in water purification technology ${ }^{1-4}$ However, the practical applications of $\mathrm{TiO}_{2}$ are limited by its large band gap $(3.2 \mathrm{eV})$, which can only active under the UV light irradiation ${ }^{5-7}$. Therefore, several strategies have been developed to shift the optical sensitivity of $\mathrm{TiO}_{2}$ from $\mathrm{UV}$ to the visible-light region for the efficient use of solar energy, such as element doping, metal deposition, surface sensitization, and coupling of composite semiconductors ${ }^{8-11}$. Recently, co-doped titania with double non-metal ${ }^{12,13}$, metal-nonmetal elements ${ }^{14-17}$ and double metal ions ${ }^{18}$ have been attracted more attention, which could further improve the photocatalytic activity of $\mathrm{TiO}_{2}$. Among these, co-doping with transition metal and nonmetal elements such as Fe-N, V-N and W-C could effectively modify the electronic structures of $\mathrm{TiO}_{2}$ and shift its absorption edge to a low energy ${ }^{16}$.

In addition, the structural properties of $\mathrm{TiO}_{2}$, such as crystalline phase, crystallite size, surface area and pore distribution, are important for its photocatalytic properties. In our previous work, we have reported that the use of hydrocarbon surfactants as the template and nonmetal doping precursor in the self-assembly sol-gel methods to tailor-design the structural properties of $\mathrm{TiO}_{2}$ from molecular

*e-mail: liugl@mail.hzau.edu.cn precursors ${ }^{19-22}$, obtain the $\mathrm{TiO}_{2}$ with high surface area, high porosity, small crystal size and narrow pore size distribution. Specifically, these hydrocarbon surfactants can serve as a nonmetal doping precursor to increase the photocatalytic activity of $\mathrm{TiO}_{2}$ under visible light irradiation ${ }^{19,20}$.

In this study, novel manganese and carbon codoped $\mathrm{TiO}_{2}$ photocatalysts with nonionic surfactant Tween 80 as a pore template and carbon doping reagent were synthesized by the sol-gel method and characterized. The photocatalytic activity of the samples was evaluated by the photocatlytic degradation of Methyl orange (MO) under simulate daylight irradiation and the effect of the calcination temperature on photocatalytic activity and phase transformation was studied.

\section{Materials and methods}

\subsection{Synthesis of $\mathrm{Mn}-\mathrm{C}-\mathrm{TiO}_{2}$}

$\mathrm{Mn}-\mathrm{C}-\mathrm{TiO}_{2}$ were prepared by the self-assembly surfactant-based sol-gel method under mild conditions as follow. A nonionic surfactant Tween 80 (T80, polyoxyethylenesorbitan monooleate, Guoyao Chemical Co.) was employed as the pore directing agent and carbon precursor in the modified sol-gel solution. $5 \mathrm{ml}$ T80 was dissolved in $20 \mathrm{ml}$ isopropyl alcohol (i-PrOH, 99.8\%, Guoyao Chemical Co.) and then $3 \mathrm{ml}$ titanium tetraisopropoxide (TTIP, 97\%, Sigma-Aldrich) was added under vigorous stirring. Finally, $3 \mathrm{ml}$ acetic acid (AcOH, Guoyao Chemical Co.) was added into the solution 
for the formation of water in the mixture. The sol-gel was aged at $65^{\circ} \mathrm{C}$ for $24 \mathrm{hrs}$. To synthesize particles, the sol was dried at room temperature for $3 \mathrm{hrs}$ and then calcined at 400 , 500 and $600{ }^{\circ} \mathrm{C}$ for $3 \mathrm{hrs}$. For comparison, the control sample was prepared though the same method, without adding the corresponding dopants and calcined at $400{ }^{\circ} \mathrm{C}$ for $3 \mathrm{hrs}$. The catalysts produced are denoted as $\mathrm{TiO}_{2}, \mathrm{Mn}-\mathrm{C}-\mathrm{TiO}_{2}-400$, $\mathrm{Mn}-\mathrm{C}-\mathrm{TiO}_{2}-500$ and $\mathrm{Mn}-\mathrm{C}-\mathrm{TiO}_{2}-600$.

\subsection{Characterization of synthesized $\mathrm{Mn}-\mathrm{C}-\mathrm{TiO}_{2}$}

The X-ray diffraction (XRD) analysis was performed on X'Pert PRO (D8 Advance) XRD diffractometer using $\mathrm{Cu}$ $\mathrm{K} \alpha(\lambda=1.5406 \AA)$ radiation to study the crystal structure and crystallinity of the Mn-C-TiO . The Brunauer-Emmett-Teller (BET) surface area, pore volume, porosity, Barret-Joyner-Halenda (BJH) pore size and distribution (based on nitrogen adsorption and desorption isotherms) were determined by a Tristar 300 (Micromeritics) porosimeter analyzer. All the tested powders were purged with nitrogen gas for $2 \mathrm{~h}$ at $150{ }^{\circ} \mathrm{C}$ using Flow prep 060 (Micromeritics). Fourier transform infrared (FT-IR) spectroscopy was carried out using Thermo Scientific Nicolet 6700 spectrometer to detect the presence of carbon group on the samples. Measurement range was $4000-500 \mathrm{~cm}^{-1}$, with a $4 \mathrm{~cm}^{-1}$ resolution, $0.475 \mathrm{~cm}^{-1} / \mathrm{s}$ scan speed and 32 scans. To investigate the light absorption and optical band gap of the synthesized $\mathrm{TiO}_{2}$, the UV - vis absorption spectra were obtained with a UV - vis spectrophotometer (Shimadzu 2450 PC) mounted with an integrating sphere accessory (ISR1200) using $\mathrm{BaSO}_{4}$ as reference standard. An X-ray photoelectron spectroscope (XPS, PerkinElmer Model 5300) was employed to determining the binding energy of $\mathrm{Mn}$ and $\mathrm{C}$. The conditions of the equipment include a takeoff angle of $45^{\circ}$ and vacuum pressure of $10^{-8}$ to $10^{-9}$ Torr. The binding energies were referenced to the $\mathrm{C} 1 \mathrm{~s}$ peak at $284.6 \mathrm{eV}$. Photoluminescence spectra (PL) were measured by Shimadzu RF-5301 PC spectrofluorophotometer $(\mathrm{EX}=240 \mathrm{~nm}, \mathrm{EM}=350-400 \mathrm{~nm})$ at roonm temperature.

\subsection{Degradation efficiency}

The effect of calcination temperature on the degradation efficiency of $\mathrm{Mn}-\mathrm{C}-\mathrm{TiO}_{2}$ was evaluated by the degradation of the degradation of methyl orange in water under the simulate daylight irradiation. Firstly, a particles suspension $(0.5 \mathrm{~g} / \mathrm{L})$ solution was prepared and dispersed using an ultrasonicator (2510R-DH, Bransonic) for $24 \mathrm{~h}$. Secondly, $50 \mu \mathrm{L}$ methyl orange solution $(50 \mathrm{~g} / \mathrm{L})$ was transferred to a $50 \mathrm{ml}$ particles suspension placed in reactor to achieve an initial concentration of $50 \mathrm{mg} / \mathrm{L}$. Finally, $50 \mu \mathrm{L} \mathrm{HNO}_{3}$ $\left(0.05 \mathrm{~mol} \mathrm{~L}^{-1}\right)$ was added into the solution. During irradiation with two fluorescent lamps (20W, Cole-Parmer) imitating daylight, the reactor was mixed continuously to minimize mass transfer limitations. A $0.2 \mathrm{~mL}$ sample was withdrawn by $1 \mathrm{~h}$. The photocatalyst was immediately removed from the samples after centrifugation. The progress of photocatalytic degradation was monitored through measuring the characteristic absorbance of the solution samples by a UV-760CRT UV-Vis spectrophotometer (Shanghai Precision \& Scientific Instrument Co., Ltd). The characteristic absorbance peaks of methyl orange shift from 460 to $517 \mathrm{~nm}$ under the acidic condition. Therefore, $\lambda_{\max }=517 \mathrm{~nm}$ was choose to measure the content of methyl orange left in the sample.

\section{Results and discussion}

\subsection{X-ray diffraction}

XRD was used to investigate the crystal structure and crystal phase of the prepared $\mathrm{Mn}-\mathrm{C}-\mathrm{TiO}_{2}$ samples. Fig. 1 shows the effect of calcinations temperature on the phase structures of $\mathrm{Mn}-\mathrm{C}-\mathrm{TiO}_{2}$ and $\mathrm{TiO}_{2}$ samples. It can be seen that the calcination temperature obviously influences the crystallization and phase composition of the $\mathrm{TiO}_{2}$. At $400^{\circ} \mathrm{C}$, only anatase $\mathrm{TiO}_{2}$ crystal phase could be identified in Mn-C-TiO and $\mathrm{TiO}_{2}$ samples and no other dopant related crystal phases could be resolved. With the calcination temperature increasing, the peak intensities of anatase increase and the width of the (101) plane diffraction peak of anatase $\left(2 \mathrm{Theta}=25.4^{\circ}\right)$ become narrower. The rutile phase appeared when the calcination temperature reached to $600{ }^{\circ} \mathrm{C}$. The average crystalline size calculated by applying the Scherrer formula on the anatase (101) diffraction peak was $12.28,16.57$ and $23.68 \mathrm{~nm}$ for the pure $\mathrm{Mn}-\mathrm{C}-\mathrm{TiO}_{2}-400$, $\mathrm{Mn}-\mathrm{C}-\mathrm{TiO}_{2}-500$ and $\mathrm{Mn}-\mathrm{C}-\mathrm{TiO}_{2}-600$ samples (shown in Table 1), respectively, which is increased as the calcination temperature increasing.

\subsection{BET surface areas and pore structure}

The $\mathrm{N}_{2}$ isothermal adsorption technique was employed to investigate the effect of calcination on the pore size variability. As shown in figure 2(a), The Barrett, Joyner and Halenda (BJH) pore size distribution of $\mathrm{Mn}-\mathrm{C}-\mathrm{TiO}_{2}-400$ was very narrow implying good homogeneity of the pores. With the calcination temperature increasing, the BJH pore size distribution of the $\mathrm{Mn}-\mathrm{C}-\mathrm{TiO}_{2}$ exhibited a systematic shift toward larger mesopores which can be associated with the severe collapse of the initial porous structure occurred for the calcinations temperature increasing. These results are in agreement with recent work on the influence of the calcination temperature on the structural characteristic of $\mathrm{TiO}_{2}^{23,24}$.

Table 1 also shows the effects of calcination temperature on the physical properties of the $\mathrm{TiO}_{2}$ powders. It has been

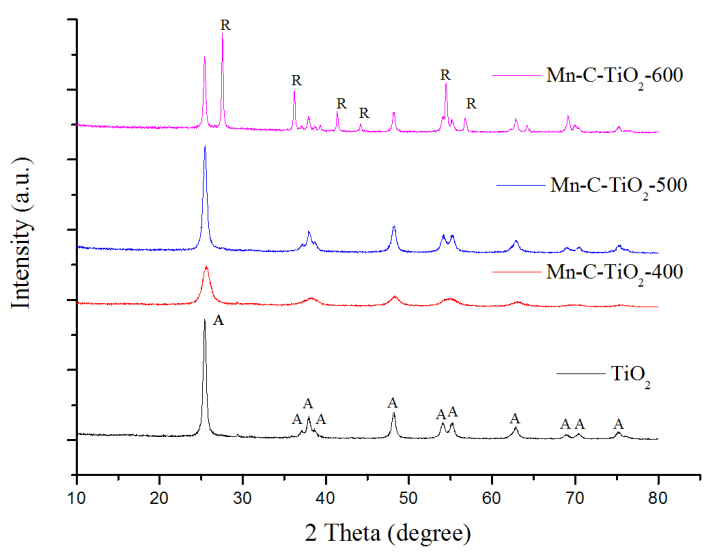

Fig. 1. XRD spectra of synthesized $\mathrm{TiO}_{2}$ and $\mathrm{Mn}-\mathrm{C}-\mathrm{TiO}_{2}$ with different calcination temperature (A : anatase, $\mathrm{R}$ : rutile). 
Table 1. Structural characteristics of $\mathrm{C}-\mathrm{TiO}_{2}$ with different oleic acid ratio and reference material

\begin{tabular}{|c|c|c|c|c|}
\hline Sample & Crystal phase $^{\mathrm{a}}$ & $\mathrm{S}_{\mathrm{BET}}\left(\mathrm{m}^{2} \mathbf{g}^{-1}\right)^{\mathrm{b}}$ & Average proe size $(\mathrm{nm})^{\mathrm{c}}$ & Crystal size (nm) \\
\hline Reference & $\mathrm{A}$ & 15.52 & 5.34 & 25.41 \\
\hline $\mathrm{Mn}-\mathrm{C}-\mathrm{TiO}_{2}-400$ & A & 142.53 & 2.49 & 12.28 \\
\hline $\mathrm{Mn}-\mathrm{C}-\mathrm{TiO}_{2}-500$ & A & 48.37 & 5.65 & 16.57 \\
\hline $\mathrm{Mn}-\mathrm{C}-\mathrm{TiO}_{2}-600$ & $\mathrm{~A}+\mathrm{R}$ & 15.68 & 9.86 & 23.68 \\
\hline
\end{tabular}
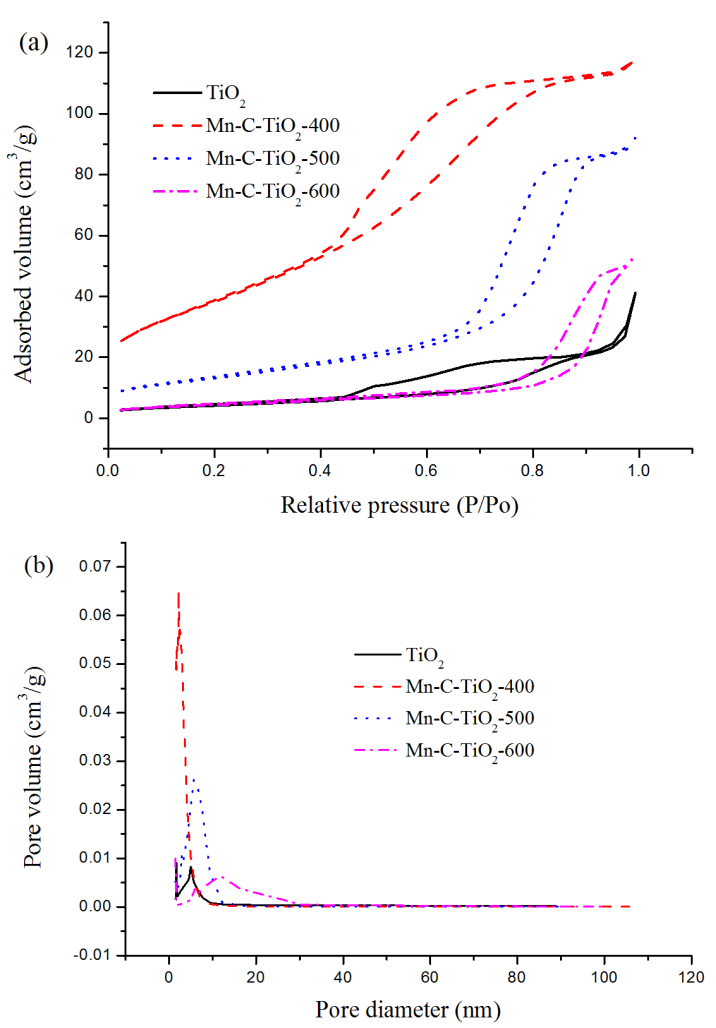

Fig. 2. $\mathrm{N}_{2}$ adsorption-desorption isotherms (a) and pore size distribution (b) of the as-prepared $\mathrm{Mn}-\mathrm{C}-\mathrm{TiO}_{2}$ powders calcined at different temperatures.

well know that the surface area plays an important role in the photocatlytic activity of $\mathrm{TiO}_{2}$, because the adsorption is the premise of photocatalytic reaction ${ }^{25,26}$. In our case, $\mathrm{Mn}-\mathrm{C}-\mathrm{TiO}_{2}$ powder calcined at $400{ }^{\circ} \mathrm{C}$ show a largest specific surface area and their values reach $142.53 \mathrm{~m}^{2} / \mathrm{g}$. With increasing calcination temperature, the specific surface areas steadily decreased due to the growth of $\mathrm{TiO}_{2}$ crystallite. At $600{ }^{\circ} \mathrm{C}$, the specific surface area decreased to $15.68 \mathrm{~m}^{2} / \mathrm{g}$. It is also easy to note that all powders show a monotonic increase in the average pore size with increasing calcination temperature. These results indicate that the calcination temperature significantly could affect the physical properties of the $\mathrm{TiO}_{2}$ powders and this is similar to previous results for the effect of calcination temperature on the $\mathrm{TiO}_{2}$ powders ${ }^{24}$.

\subsection{FT-IR analysis}

To give additional evidence and further to confirm the effect of calcinations temperature on the manganese and carbon doping, FT-IR characterizations were preformed. The infrared spectroscopy of $\mathrm{Mn}-\mathrm{C}-\mathrm{TiO}_{2}$ samples calcined at different temperatures was presented in Fig. 3. The bands at

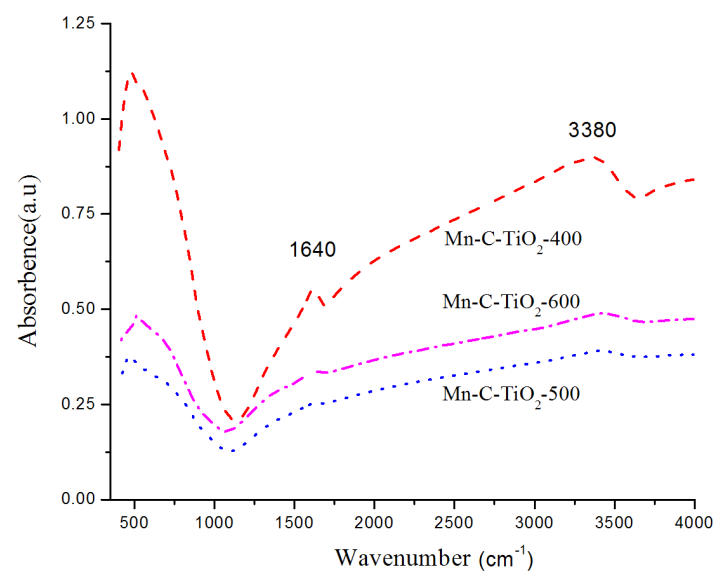

Fig. 3. FT-IR spectra of $\mathrm{Mn}-\mathrm{C}-\mathrm{TiO}_{2}$ powders calcined at different temperatures.

$1640 \mathrm{~cm}^{-1}$ and the wide bands at $3100-3700 \mathrm{~cm}^{-1}$ are resultant from $\mathrm{O}-\mathrm{H}$ stretching of adsorbed water molecules and the surface hydroxyl groups on $\mathrm{TiO}_{2}$ have been recognized to play an important role in the photocatalytic process, as these groups can inhibit the recombination of photogeneration charges and interact with photogenerated holes to product reactive oxygen species ${ }^{27}$. However, It can be seen that the intensity of these two peaks decreased with the calcination temperature increasing, which will reduce the photocatalytic efficiency of Mn-C-codoped $\mathrm{TiO}_{2}$. Usually, the bands at $2330 \mathrm{~cm}^{-1}$ are assigned to the stretching vibrations of the $\mathrm{C}=\mathrm{O}$ bonds [19]. In our case, we can not find this peak which demonstrate that none carbon species exist on the surface of powder. In the region below $1000 \mathrm{~cm}^{-1}$, the peak was ascribed to absoption bands of $\mathrm{Mn}-\mathrm{O}$, which could be inferred that some manganese oxide may appear on the surface of $\mathrm{TiO}_{2}{ }^{28}$.

\subsection{UV-vis diffuse reflectance spectra}

It is well know that the photocatalytic activity of a semiconductor is related to its light absorption ability. Fig. 4 shows the UV-vis absorption spectra of the $\mathrm{Mn}-\mathrm{C}-\mathrm{TiO}_{2}$ samples. The typical onset of absorption near $380 \mathrm{~nm}$ can be assigned to the intrinsic band gap absorption of $\mathrm{TiO}_{2}{ }^{29}$. We can find that there is a significant shift in the onset absorption toward the higher wavelength for the $\mathrm{Mn}-\mathrm{C}-\mathrm{TiO}_{2}$ sample. The band gap energy was estimated by plotting $\mathrm{F}(\mathrm{R})^{1 / 2}$ as a function of the photon energy $(h v)^{19}$. The values of the band gap for $\mathrm{Mn}-\mathrm{C}-\mathrm{TiO}_{2}-400$ and reference $\mathrm{TiO}_{2}$ were accordingly determined by the linear extrapolation the high slope of the corresponding curve (Inset in Fig. 4). A significant reduction of the band gap energy for $\mathrm{Mn}-\mathrm{C}-\mathrm{TiO}_{2}-400(2.72 \mathrm{eV})$ was thus derived compared to $3.18 \mathrm{eV}$ for the reference $\mathrm{TiO}_{2}$, which is very close to that of the anatase $\mathrm{TiO}_{2}$ phase $(3.2 \mathrm{eV})$. 


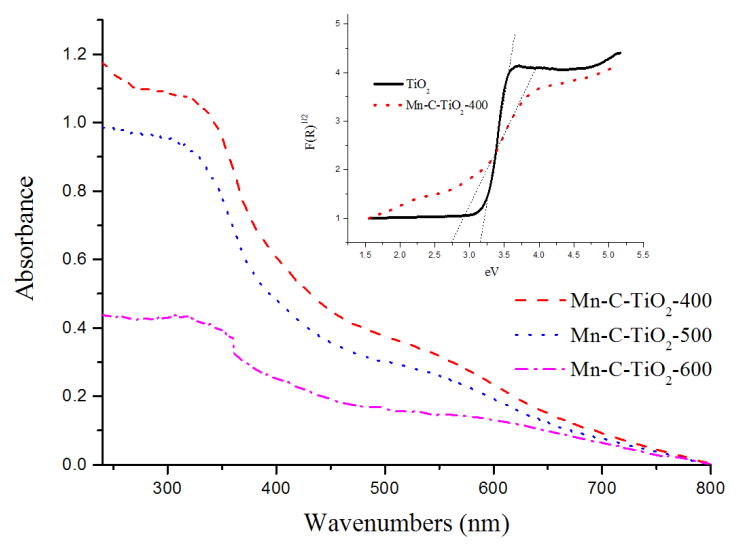

Fig. 4. UV-vis absorption properties of $\mathrm{Mn}-\mathrm{C}-\mathrm{TiO} 2$ with different calcination temperature (Insert is the banding energy of $\mathrm{Mn}-\mathrm{C}-\mathrm{TiO}_{2}-400$ and $\mathrm{TiO}_{2}$ )

The reason may due to the new electronic state in the middle of the $\mathrm{TiO}_{2}$ band gap, charge-transfer transition between the $\mathrm{d}$ electrons of the dopant and the $\mathrm{CB}$ of $\mathrm{TiO}_{2}$, the narrowed band gap resulted by $\mathrm{C}$-doping, allowing visible light absorption ${ }^{30}$. It has been reported that non-metal elements could reduce the band gap energy of $\mathrm{TiO}_{2}$ by mixing their $\mathrm{p}$ orbital of non-metal with $\mathrm{O} 2 \mathrm{p}$ orbital and the doping of various transitional metal ions into $\mathrm{TiO}_{2}$ could shift its optical absorption edge from UV to visible light range without a prominent change in $\mathrm{TiO}_{2}$ band gap ${ }^{31}$. From our results, the red shift of $\mathrm{Mn}-\mathrm{C}-\mathrm{TiO}_{2}$ samples in the visible light region decreased with the calcination temperature increasing, which should be attributed to the carbon disappeared with the calcination temperature increasing.

\subsection{XPS spectra}

Fig. 5 shows the XPS spectra of Mn 2p and C1s of $\mathrm{Mn}-\mathrm{C}-\mathrm{TiO}_{2}-400$ sample, which has been reported in our previous paper ${ }^{32}$. Fig. 5a shows the high-resolution $\mathrm{Mn}$ $2 p$ XPS spectra of $\mathrm{Mn}-\mathrm{C}-\mathrm{TiO}_{2}$. The two $\mathrm{Mn} 2 \mathrm{p}$ peaks at the binding energy of 640.5 and $653.0 \mathrm{eV}$ indicate the existence of $\mathrm{MnO}_{2}$ [28]. The $\mathrm{C} 1 \mathrm{~s}$ XPS spectra of $\mathrm{TiO}_{2}$ and $\mathrm{Mn}-\mathrm{C}-\mathrm{TiO}_{2}-400$ were shown in Fig. 5b. Only one peak at $284.6 \mathrm{eV}$ was found for pure $\mathrm{TiO}_{2}$, which arises from adventitious elemental carbon. But three broad but well separated peaks were observed in the $\mathrm{C} 1 \mathrm{~s}$ binding region at 281.3, 284.6 and $288.2 \mathrm{eV}$ for the as-synthesized $\mathrm{Mn}-\mathrm{C}-\mathrm{TiO}_{2}$ samples. The peak at the lower binding energy has been accordingly assigned to the formation of Ti-C bonds in $\mathrm{C}-\mathrm{TiO}_{2}$ in the previous reported ${ }^{19}$. The highest $\mathrm{C} 1 \mathrm{~s}$ energy peak at 288.2 has been accordingly interpreted as the distinct feature of $\mathrm{C}-\mathrm{O}$ bond formation in $\mathrm{Mn}-\mathrm{C}-\mathrm{TiO}_{2}$ that in principle arises from interstitial and/or substitutional (for Ti) $\mathrm{C}$ atoms, while the underlying carbonate species have been considered as the source of the extended optical absorption tail of $\mathrm{Mn}-\mathrm{C}-\mathrm{TiO}_{2}$ in the visible range ${ }^{33}$. In the present case, the co-existence of the 281.3 and $288.2 \mathrm{eV} \mathrm{C1s} \mathrm{peaks} \mathrm{corresponding} \mathrm{to} \mathrm{the}$ binding energies of Ti-C and C-O bonds indicates both the presence of interstitial $\mathrm{C}$ atoms as well as carbon substitution for $\mathrm{O}$ and $\mathrm{Ti}$ atoms in the titania lattice.
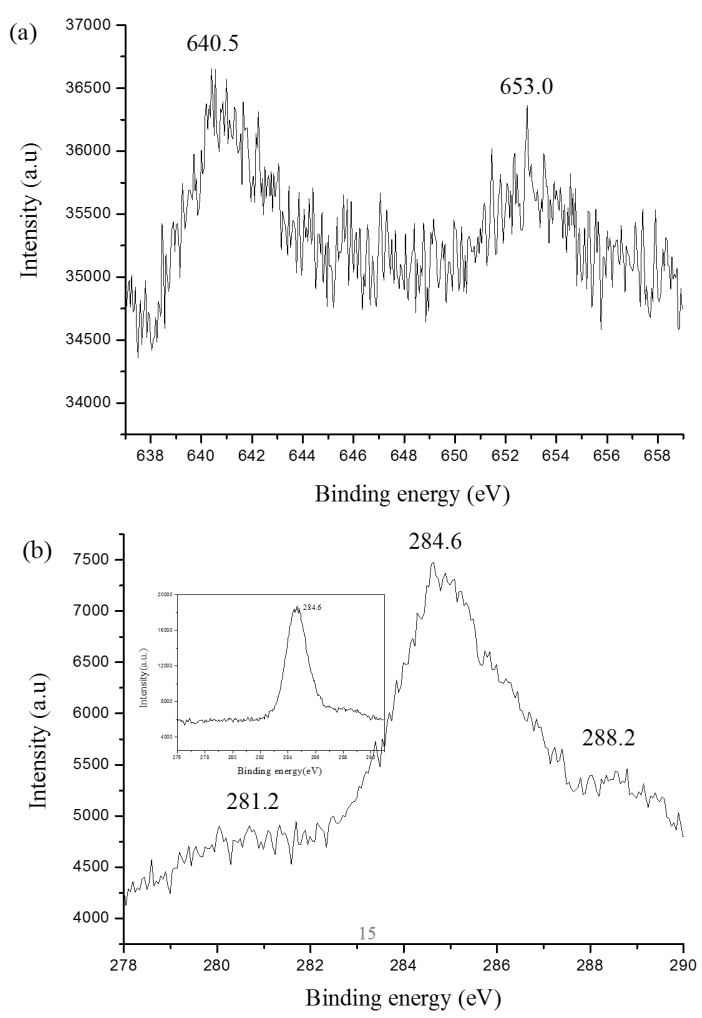

Fig. 5. XPS spectra of $\mathrm{Mn}-\mathrm{C}-\mathrm{TiO}_{2}$ nanopartile calcined at $400{ }^{\circ} \mathrm{C}$. (a) a spectrum of $\mathrm{Mn} 2 \mathrm{p}$, (b) a spectrum of $\mathrm{C} 1 \mathrm{~s}$ (insert is the $\mathrm{C} 1 \mathrm{~s}$ spectrum of reference sample).

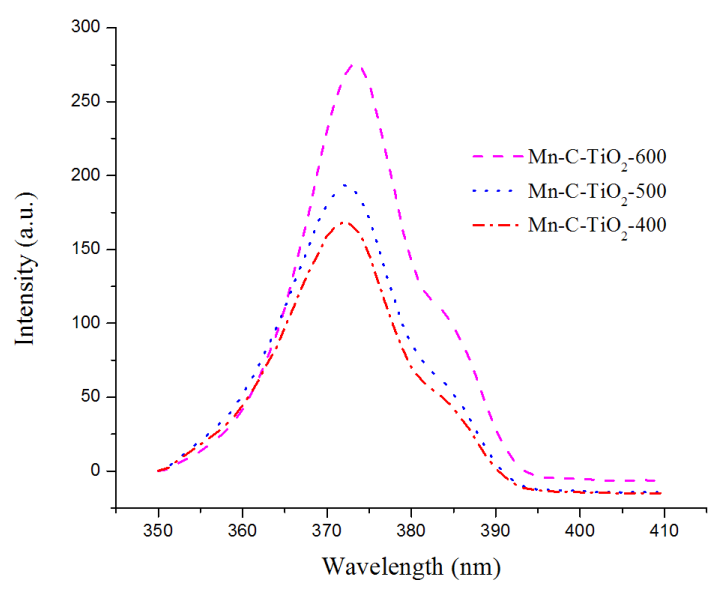

Fig. 6. The photoluminescence spectra for $\mathrm{Mn}-\mathrm{C}-\mathrm{TiO}_{2}$ nanopartiles calcined at different temperatures.

\subsection{Photoluminescence spectra}

The PL emission spectra has been widely used to disclose the efficiency of charge carrier trapping, immigration, and transfer, and to understand the fate of electrons and holes in semiconductor since PL emission results from the recombination of free carriers ${ }^{34-37}$. Fig. 6 illustrates that the PL spectra of $\mathrm{Mn}-\mathrm{C}-\mathrm{TiO}_{2}$ samples calcined at 400,500 and $600{ }^{\circ} \mathrm{C}$ in the range of 350-400 nm under a $300 \mathrm{~nm}$ wavelength excitation source, respectively. An obvious emission intensity peaks 

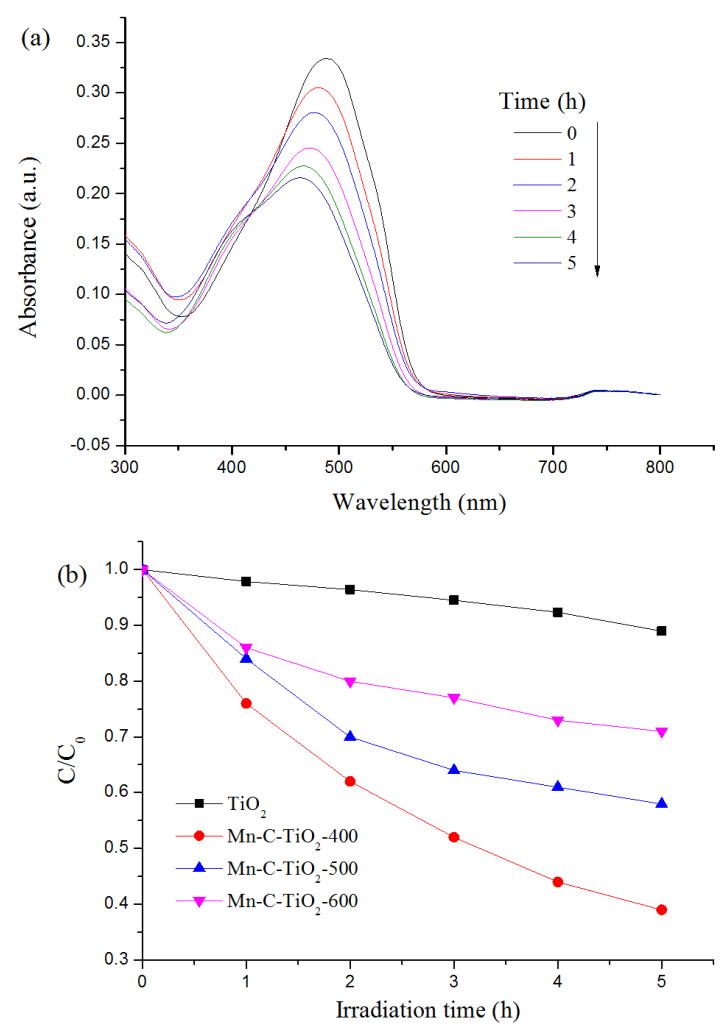

Fig. 7. (a) Absorbane spectra of methyl orange solution in presence of $\mathrm{Mn}-\mathrm{C}-\mathrm{TiO}_{2}$ calcined at $400{ }^{\circ} \mathrm{C}$ under the daylight irradiation. (b) Photodegradation of methyl orange with $\mathrm{Mn}-\mathrm{C}-\mathrm{TiO}_{2}$ calcined at different temperatures.

could be observed for the $\mathrm{Mn}-\mathrm{C}-\mathrm{TiO}_{2}$ samples catalyst at $372 \mathrm{~nm}$ which was ascribed to the free exciton emission reported by $\mathrm{Yu}$ et al. ${ }^{38}$. The three spectras showed nearly similar curve shape except for the peak intensities. As seen from the spectra, the PL intensity sharply increased as the calcination temperature increased. It was well known that the PL intensity was closely related to the surface defects of the materials. The sample calcined at $400{ }^{\circ} \mathrm{C}$ possessed the lowest PL intensity, revealing that the photo-generated holes and electrons had the lowest recombination rate in the samples.

\subsection{Photocatalytic activity of samples in photodegradation of $\mathrm{Mn}-\mathrm{C}-\mathrm{TiO}_{2}$}

To evaluate the effect of calcination temperature on the photocatalytic activity of the $\mathrm{Mn}-\mathrm{C}-\mathrm{TiO}_{2}$ sample, the reactions of methyl orange degradation were preformed as photoreaction probes under the daylight irradiation. Fig. 7 shows the relationship of methyl orange degradation and calcinations temperatures. It could be found that the

\section{References}

1. Savio AK, Fletcher J, Smith K, Iyer R, Bao JM, Hernández FC. Environmental effective photocatalyst $\mathrm{CoO}-\mathrm{Ti}_{2}$, synthesized by thermal precipitation of $\mathrm{C} 0$ in amorphous. Applied Catalysis B. 2016;182:449-455. degradation phenomenon occurred for pure $\mathrm{TiO}_{2}$ sample, which could be attributed to the adsorption and photocatalytic degradation induced by trace UV light in the reaction system. For the $\mathrm{Mn}-\mathrm{C}-\mathrm{TiO}_{2}$ sample, the sample calcined at $400{ }^{\circ} \mathrm{C}$ shows the highest photocalytic activity, which reached to the $85 \%$ after the irradiation for $4 \mathrm{hrs}$. With the calcination temperature increasing, the degradation rate of methyl orange decreased. It is well known that titania has three different crystalline phase: anatase, rutile and brookite and the rutile has the lowest photocatalytic activity. The decrease in the photocatalytic activity with the calcination temperature increasing is due to the following factors. First, according to XRD results, the phase transformation of anatase to rutile occurred when the calcination temperature reached to $600^{\circ} \mathrm{C}$. Second, the sintering and growth of $\mathrm{TiO}_{2}$ crystallites result in the significant decrease of surface area of the $\mathrm{Mn}-\mathrm{C}-\mathrm{TiO}_{2}$ samples. Also, the carbon loss with calcination temperature increasing promoted the recombination of photo-generated holes and electrons. These causes may result in the decrease in photocatalytic activity.

\section{Conclusions}

In conclusion, we have synthesized the manganese and carbon codoped $\mathrm{TiO}_{2}$ as novel catalysts by surfactant-based sol-gel methods under mild conditions. For comparison, pure $\mathrm{TiO}_{2}$ were also prepared by the same method without adding the corresponding dopants. Detailed characterizations of the materials physicochemical properties were carried out. The $\mathrm{Mn}-\mathrm{C}-\mathrm{TiO}_{2}$ sample calcined at $400{ }^{\circ} \mathrm{C}$ shows the anatase phase and the rutile phase appears when the calcination temperature reach to $600{ }^{\circ} \mathrm{C}$. The photocatalytic activity of $\mathrm{Mn}-\mathrm{C}-\mathrm{TiO}_{2}$ samples strongly depends on the calcination temperature. When the calcination temperature was from $400{ }^{\circ} \mathrm{C}$ to $600{ }^{\circ} \mathrm{C}$, the photocatalytic activity of $\mathrm{Mn}-\mathrm{C}-\mathrm{TiO}_{2}$ decreased due to the carbon disappeared and rutile phase $\mathrm{TiO}_{2}$ appeared. At $400{ }^{\circ} \mathrm{C}$, the $\mathrm{TiO}_{2}$ powders shows the highest photocatalytic activity due to high specific surface area and small particle size distribution. Moreover, the $\mathrm{Mn}-\mathrm{C}-\mathrm{TiO}_{2}$ sample calcined at $400{ }^{\circ} \mathrm{C}$ shows the lowest PL intensity due to the decrease in the recombination rate of photogenerated electrons and holes, which also can increase the photocalytic activity of manganese and carbon codoped $\mathrm{TiO}_{2}$.

\section{Acknowledges}

This research was financially supported by the National Natural Science Foundation of China (41401547), Natural Science Foundation of Hubei Province of China (2014CFB283), China Postdoctoral Science Foundation (2013M540619, 2015T80855) and Open Project of State Key Laboratory of Freshwater Ecology and Biotechnology (2015FB04).

2. Naldoni A, Allieta M, Santangelo S, Marelli M, Fabbri F, Cappelli S, Bianchi CL, Psaro R, Santo VD. Effect of nature and location of defects on bandgap narrowing in black $\mathrm{TiO}_{2}$ nanoparticles. Journal of American Chemical Society. 2012;134(18):76007603. 
3. Wu Q, Zhao J, Qin G, Wang C, Tong X, Xue S. Photocatalytic reduction of $\mathrm{Cr}(\mathrm{VI})$ with $\mathrm{TiO}_{2}$ film under visible light. Applied Catalysis B. 2013;142-143:142-148. DOI: 10.1016/j. apcatb.2013.04.056

4. Thomas J, Radhika S, Yoon M. $\mathrm{Nd}^{3+}$-doped $\mathrm{TiO}_{2}$ nanoparticles incorporated with heteropoly phosphotungstic acid: A novel solar photocatalyst for degradation of 4-chlorophenol in water Journal of Molecular Catalysis A. 2016;411:146-156. DOI: 10.1016/j.molcata.2015.10.021

5. Kuo YL, Su T, Kung F, Wu T. A study of parameter setting and characterization of visible-light driven nitrogen-modified commercial $\mathrm{TiO}_{2}$ photocatalysts. Journal of Hazardous Materials. 2011;190(1):938-944. doi:10.1016/j.jhazmat.2011.04.031

6. Song X, Hu Y, Zheng M, Wei C. Solvent-free in situ synthesis

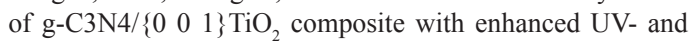
visible-light photocatalytic activity for NO oxidation. Applied Catalysis B. 2016;182:587-597. doi:10.1016/j.apcatb.2015.10.007

7. Miao G, Ye F, Wu L, Ren X, Xiao J, Li Z, Wang H. Selective adsorption of thiophenic compounds from fuel over $\mathrm{TiO}_{2} /$ $\mathrm{SiO}_{2}$ under UV-irradiation. Journal of Hazardous Materials. 2015;300:426-432. DOI: 10.1016/j.jhazmat.2015.07.027

8. Wang S, Liu C, Dai K, Cai P, Chen H, Yang C, Huang Q. Fullerene $\mathrm{C}_{70}-\mathrm{TiO}_{2}$ hybrids with enhanced photocatalytic activity under visible light irradiation. Journal of Material Chemistry A. 2015;3:21090-21098. DOI: 10.1039/C5TA03229F

9. Luo X, Deng F, Min L, Luo S, Guo B, Zeng G, et al. Facile onestep synthesis of inorganic-framework molecularly imprinted $\mathrm{TiO}_{2} / \mathrm{WO}_{3}$ nanocomposite and its molecular recognitive photocatalytic degradation of target contaminant. Environmental Science \& Technology. 2013;47(13):7404-7412. DOI: 10.1021/ es4013596

10. Papadimitriou VC, Stefanopoulos VG, Romanias MN, Papagiannakopoulos P, Sambani K, Tudose V, et al. Determination of photo-catalytic activity of un-doped and Mn-doped $\mathrm{TiO}_{2}$ anatase powders on acetaldehyde under UV and visible light. Thin Solid Films. 2011;520(4):1195-1201. doi:10.1016/j. tsf.2011.07.073

11. Gao T, Sun G, Cheng F, Dai K, Chen H, Deng K, et al. Enhanced visible-light-driven photoactivities of single-walled carbon nanotubes coated with $\mathrm{N}$ doped $\mathrm{TiO}_{2}$ nanoparticles. $R C S$ Advances. 2015;5:28973-28979. DOI: 10.1039/C4RA16597G, Paper

12. Hassan ME, Chen J, Liu G, Zhu D, Cai J. Enhanced Photocatalytic Degradation of Methyl Orange Dye under the Daylight Irradiation over CN-TiO ${ }_{2}$ Modified with OMS-2. Materials. 2014;7:80248036. doi:10.3390/ma7128024

13. Lin L, Zheng RY, Xie JL, Zhu YX, Xie YC. Synthesis and characterization of phosphor and nitrogen co-doped titania. Applied Catalysis B. 2007;76(1-2):196-202. doi:10.1016/j. apcatb.2007.05.023

14. Shi J, Cui H, Zong X, Chen S, Chen J, Xu B, et al. Facile one-pot synthesis of $\mathrm{Eu}, \mathrm{N}$-codoped mesoporous titania microspheres with yolk-shell structure and high visible-light induced photocatalytic performance. Applied Catalysis A. 2012;435-436:86-92.

15. Ma Y, Zhang J, Tian B, Chen F, Wang L. Synthesis and characterization of thermally stable $\mathrm{Sm}, \mathrm{N}$ co-doped $\mathrm{TiO}_{2}$ with highly visible light activity. Journal of Hazardous Materials. 2010;182:386-393.

16. Yang X, Cao C, Hohn K, Erickson L, Maghrang R, Hamal D, et al. Highly visible-light active $\mathrm{C}$ - and $\mathrm{V}$-doped $\mathrm{TiO}_{2}$ for degradation of acetaldehyde. Journal of Catalysis. 2007;252:2296-302.

17. Xin W, Zhu D, Liu G, Hua Y, Zhou W. Synthesis and characterization of $\mathrm{Mn}-\mathrm{C}-\mathrm{Codoped}$ nanoparticles and photocatalytic degradation of methyl orange dye under sunlight irradiation. International
Journal of J Photoenergy. 2012(2012):767905. http://dx.doi. org/10.1155/2012/767905

18. Chen HY, Lo SL, Ou HH. Catalytic hydrogenation of nitrate on $\mathrm{Cu}-\mathrm{Pd}$ supported on titanate nanotube and the experiment after aging, sulfide fouling and regeneration procedures. Applied Catalysis B. 2013;142-143:65-71. DOI: 10.1016/j. apcatb.2013.05.004

19. Liu G, Han C, Pelaez M, Zhu D, Liao S, Likodimos V, et al. Synthesis, characterization and photocatalytic evaluation of visible light activated C-doped $\mathrm{TiO}_{2}$ nanoparticles. Nanotechnology. 2012; 23(29):294003.

20. Liu G, Han C, Pelaez M, Zhu D, Liao S, Likodimos V, et al. Enhanced visible light photocatalytic activity of C-N-codoped $\mathrm{TiO}_{2}$ films for the degradation of microcystin-LR. Journal of Molecular Catalysis A. 2013;372:58-65.

21. Han C, Pelaez M, Likodimos V, Kontos AG, Falaras P, O'Shea $\mathrm{K}$, Dionysiou DD. Innovative visible light-activated sulfur doped $\mathrm{TiO}_{2}$ films for water treatment. Applied Catalysis $B$. 2011;107(1-2):77-87. doi:10.1016/j.apcatb.2011.06.039

22. Pelaez M, de la Cruz AA, Stathatos E, Falaras P, Dionysiou DD. Visible light-activated N-F-codoped $\mathrm{TiO}_{2}$ nanoparticles for the photocatalytic degradation of microsystin LR in water. Catalysis Today. 2009;144:19-25.

23. Choi H, Antoniou MG, Pelaez M, de la Cruz AA, Shoemaker JA, Dionysiou DD. Mesoporous nitrogen-doped $\mathrm{TiO}_{2}$ for thephtocatalytic destruction of the cyanobacterial toxin microcystin-LR under visible light irradiation. Environmental Science Technology. 2005;41:7530-7535.

24. Pelaez M, Falaras P, Likodimos V, Kontos AG, de la Cruz AA, O'Shea K, et al . Synthesis, structural characterization and evaluation of sol-gel-bases $\mathrm{NF}^{-\mathrm{TiO}_{2}}$ films with visible lightphotoactivation for the removal of microcystin-LR. Applied Catalysis B. 2010;99:378-387.

25. Avilés-García O, Espino-Valencia J, Romero R, Rico-Cerda JL, Natividad R. Oxidation of 4-Chlorophenol by mesoporous titania: effect of surface morphological characteristics. International Journal of Photoenergy. 2014(2014);210751. http://dx.doi. org/10.1155/2014/210751

26. Lu N, Yu HT, Su Y, Wu Y. Water absorption and photocatalytic activity of $\mathrm{TiO}_{2}$ in a scrubber system for odor control at varying pH . Separation and Purification Technology. 2012;90:196-203.

27. Huang Y, Ho WK, Lee SC, Zhang LZ, Fan XX, Zou ZG. Effect of carbon doping on the mesoporous structure of nanocrystalline titanium dioxide and its solar-light-Driven Photocatalytic Degradation of Nox. Langmuir. 2008;24:3510-3516. DOI: 10.1021/1a703333z

28. Liu G, Liao S, Zhu D, Cui J, Zhou W. Solid-phase photocatalytic degradation of polyethylene film with manganese oxide OMS-2. Solid State Science. 2011;13(1):88-94. doi:10.1016/j. solidstatesciences.2010.10.014

29. Wang X, Tang Y, Leiw M, Lim T. Solvothermal synthesis of Fe-C codoped $\mathrm{TiO} 2$ nanoparticles for visible-light photocatalytic removal of emerging organic contaminants in water. Applied Catalysis A. 2011;409-410:257-266. doi:10.1016/j.apcata.2011.10.011

30. Hamadanian M, Reisi-Vanani A, Behpour M, Esmaeily AS. Synthesis and characterization of Fe,S-codoped $\mathrm{TiO}_{2}$ nanoparticles: Application in degradation of organic water pollutants. Desalination. 2011;281:319-324. doi:10.1016/j. desal.2011.08.028

31. Liu S, Yu J, Cheng B, Jaroniec M . Fluorinated semiconductor photocatalysts: tunable synthesis and unique properties. Advances Colloid and Interface Science. 2012;173:35-53. 
32. Xin W, Zhu D, Liu G, Hua Y, Zhou W. Synthesis and characterization of Mn-C-Codoped Nanoparticles and photocatalytic degradation of methyl orange dye under sunlight irradiation. International Journal of Photoenergy. 2012(2012):767905.

33. Matos J, Garcia A, Zhao L, Titirici MM. Solvothermal carbondoped $\mathrm{TiO}_{2}$ photocatalyst for the enhanced methylene blue degradation under visible light. Applied Catalysis A. 2010;390(12):175-182. doi:10.1016/j.apcata.2010.10.009

34. Li Y, Zhang H, Hu X, Zhao X, Han M. Efficient VisibleLight-Induced Photocatalytic Activity of a 3D-Ordered Titania Hybrid Photocatalyst with a Core/Shell Structure of Dye-Containing Polymer/Titania. The Journal of Physical Chemistry. 2008;112:14973-14979. DOI: 10.1021/jp8055152

35. Li Y, Zhang H, Guo Z, Han J, Zhao X, Zhao Q, et al. Highly efficient visible-light-induced photocatalytic activity of nanostructured
$\mathrm{AgI} / \mathrm{TiO}_{2}$ photocatalyst. Langmuir. 2008;24(15):8351-8357. DOI: $10.1021 / 1 \mathrm{a} 801046 \mathrm{u}$

36. Thomas J, Yoon M. Facile synthesis of pure $\mathrm{TiO}_{2}(\mathrm{~B})$ nanofibers doped with gold nanoparticles and solar photocatalytic activities. Applied Catalysis B. 2012;111-112:502-508. DOI: 10.1016/j. apcatb.2011.10.039

37. Xie W, Li Y, Sun W, Huang J, Xie H, Zhao X. Surface modification of $\mathrm{ZnO}$ with $\mathrm{Ag}$ improves its photocatalytic efficiency and photostability. Journal of Photochemistry and Photobiology A. 2010;216:149-155.

38. Yu J, Yu H, Cheng B, Zhao X, Yu JC, Ho WK. The effect of calcination temperature on the surface microstructure and photocatalytic activity of $\mathrm{TiO}_{2}$ thin films prepared by liquid phase deposition. Journal of Physical Chemistry B. 2003;107:1387113879. 